\title{
A high oleic sunflower oil fatty acid esters of plant sterols mixed with dietary diacylglycerol reduces plasma insulin and body fat accumulation in Psammomys obesus
}

\author{
Ehud Ziv*1, Natan Patlas', Rony Kalman², Dori Pelled ${ }^{3,4}$, Yael Herzog 3 , \\ Tali Dror ${ }^{3}$ and Tzafra Cohen ${ }^{3}$
}

\begin{abstract}
Address: ${ }^{1}$ Diabetes Research Unit, Hadassah Medical Center and The Hebrew University, Jerusalem 91120, Israel, ${ }^{2}$ Animal facility, Hebrew University, Jerusalem, Israel, ${ }^{3}$ R\&D Department, Enzymotec LTD, Migdal-HaEmeq, Israel and ${ }^{4}$ Current address: Medical Department, NiTi Surgical solutions, Netanya, Israel

Email: Ehud Ziv* - ehud@hadassah.org.il; Natan Patlas - patlas@hadassah.org.il; Rony Kalman - ronyk@savion.huji.ac.il;

Dori Pelled - dori@nitisurgical.com; Yael Herzog - yael@enzymotec.com; Tali Dror - talid@enzymotec.com;

Tzafra Cohen - Tzafra@enzymotec.com

* Corresponding author
\end{abstract}

Published: 12 October 2009

Lipids in Health and Disease 2009, 8:42 doi:10.1186/1476-5IIX-8-42

This article is available from: http://www.lipidworld.com/content/8///42

(c) 2009 Ziv et al; licensee BioMed Central Ltd.

This is an Open Access article distributed under the terms of the Creative Commons Attribution License (http://creativecommons.org/licenses/by/2.0), which permits unrestricted use, distribution, and reproduction in any medium, provided the original work is properly cited.
Received: 7 September 2009

Accepted: 12 October 2009

\begin{abstract}
Background: Metabolic syndrome is associated with subsequent development of cardiovascular diseases and type 2 diabetes. It is characterized by reduced response to insulin, central obesity, and dyslipidemia. Intake of plant sterols (PS) has been shown to confer a healthier lipid profile and ameliorate cardiovascular disease risk factors in experimental animals and humans. In this study we used an animal model of type 2 diabetes to assess the effects of a preparation of PS esterified to high oleic sunflower oil fatty acids mixed with dietary diacylglycerol (PS-HOSO) on diabetic related metabolic parameters. Psammomys obesus (P. obesus) were fed high energy (HE) diet supplemented by either PS-HOSO or control oil. Following 4.5 weeks of intervention, animals were divided into fasting and non-fasting modes prior to outcome measurements. Glucose and insulin levels as well as blood lipid profile, body weight, and fat accumulation were evaluated in fasting and non-fasting modes.
\end{abstract}

Results: $P$. obesus fed with a HE diet displayed a characteristic heterogeneity in their blood glucose and insulin levels with a subset group displaying type 2 diabetes symptoms. PS-HOSO treatment significantly reduced total cholesterol $(24 \%, P<0.00 \mathrm{I})$ and non-HDL cholesterol $(34 \%, P<0.0 \mathrm{I})$ compared to the control diet. Among fasting animals, body weight at end point and epididymal fatto-liver weight ratio were significantly $(P<0.05$ each) reduced $(7 \%$ and $16 \%$, respectively) compared to controls. Interestingly, fasting blood glucose levels were similar between groups, whereas plasma insulin level at end point was $44 \%$ lower in the PS-HOSO group compared to control group $(P<0.000 I)$

Conclusion: PS-HOSO supplementation to diabetes-prone gerbils counteracts the increase in body weight and epididymal fat accumulation, and also results in a drop in circulating insulin levels. These effects are pointing out that PS-HOSO may serve as a functional ingredient for metabolic syndrome or diabetic sufferers, which not only influences body weight, but also prevents or reverses insulin resistance and hyperlipidemia. 


\section{Background}

Metabolic syndrome represents a cluster of metabolic disturbances that attained almost epidemic proportions worldwide and is associated with subsequent development of type 2 diabetes mellitus and cardiovascular disease $[1,2]$. It is characterized by central obesity $[3,4]$, hypertension, hyperglycemia and reduced response to insulin (insulin resistance). In addition, metabolic syndrome sufferers display various degrees of dyslipidemia. The main lipid metabolism abnormalities seen in these subjects are increased plasma triglycerides (TG) and reduced high-density lipoprotein cholesterol (HDL-c) levels, along with a predominance of small low-density lipoprotein (LDL) particles [5]. It has therefore been proposed that alteration of the fat metabolism is a critical factor that may precipitate the etiology of the disease, at least in some cases. Favourable modifications of the lipid profile in sufferers of metabolic syndrome or type- 2 diabetes, may be achieved by pharmaceutical means [6,7]. Recently, dietary supplements and functional foods have been increasingly used as lipid-lowering agents [8,9]. Intake of the n-9 monounsaturated fatty acid, oleic acid, was shown to be inversely correlated with ischemic heart disease presumably due to hypolipidemic effects [10]. This notion was further confirmed in several clinical intervention trials [1113]. Plant sterols (PS) were also reported to have significant cholesterol-lowering properties [14]. Accordingly, PS Intake decreased circulating cholesterol concentrations via the suppression of intestinal absorption due to the higher affinity of PS to micelles $[15,16]$. Recent works have shown that PS incorporated into food matrices such as margarines and spreads or in the form of dietary supplements are bioactive for long term treatment periods $[17,18]$.

Israeli sand rat Psammomys obesus, (P. obsesus), a desert gerbil species has been extensively used as a genetically heterogeneous model for type 2 diabetes. P. obesus closely resembles some human populations in which a subset of the population goes on to develop diabetes when fed a high energy diet $[19,20]$. The course of the disease development in these animals can be divided into four phases: Phase A, normoinsulinemia and normoglycemia; phase $\mathrm{B}$, hyperinsulinemia and normoglycemia; phase $\mathrm{C}$, overt diabetes, characterized by hyperinsulinemia and hyperglycemia; and phase D, hypoinsulinemia and severe hyperglycemia as a result of $\beta$-cell degranulation, and markedly reduced pancreatic insulin content [21]. As in humans, obesity and increase in body fat underlie the development of type 2 diabetes.

We have previously shown the efficacy of preparations of PS esterified to high oleic oil fatty acids in reducing total cholesterol (TC) levels in experimental animals [22] and humans [23]. In addition, the preparations were shown to reduce plasma lipid peroxidation.

In the present study, we investigated the effect of PS esterified to high oleic sunflower oil (HOSO) fatty acids mixed with dietary diacylglycerol (DAG) in HOSO matrix (PSHOSO) or soybean oil on the development of metabolic syndrome and diabetic symptoms in P. obesus.

\section{Methods \\ Animals and diets}

Sixty male Psammomys obesus gerbils were obtained from Harlan Laboratories Ltd (Jerusalem, Israel). After weaning, the animals were maintained on a low-energy diet containing $2.38 \mathrm{kcal} / \mathrm{g}$ (Koffolk, Petach Tikva, Israel) by Harlan Laboratories Ltd. Our experiment started when the animals were 2.0 to 3.5 months old. The animals were then randomly assigned to two different high-energy diets for 4.5 weeks:

1. Control HE (high energy) diet: $938.5 \mathrm{~g} / \mathrm{Kg}$ version of 2018SC+F Harlan Tekled Ltd, USA, supplemented with soybean oil to a final fat concentration of $6 \%$.

2. PS-HOSO diet (custom-made, Harlan Tekled Ltd, USA): $939 \mathrm{~g} / \mathrm{Kg}$ version of 2018SC+F, Harlan Tekled Ltd, USA, supplemented with PS-HOSO to a final fat concentration of $6 \%$. PS-HOSO constituted $4 \% \mathrm{w} / \mathrm{w}$ of total diet and comprised $20 \%$ plant sterols esterified with high oleic sunflower oil, and 15\% canola oil-based diacylglycerol (DAG).

This diet was made from a slightly concentrated version of $2018 C S+F$ with $2 \%$ fat source basal mix. Standard milling procedure was used to incorporate treatment oil into standard gerbil chow.

The animals were housed in polypropylene cages at a constant temperature of 22 to $23^{\circ} \mathrm{C}$ in a humidity-controlled animal facility with a 12 -h light/dark cycle. Free access to water and food was provided. The animals were monitored for body weight and tail blood glucose concentrations, from the beginning of the intervention and throughout (every 2-5 days), for 4.5 weeks. At endpoint, half of each group of gerbils was deprived of food overnight $(16 \mathrm{~h})$, and then all animals were lightly anaesthetized with ketamine (Ketalar; Parke-Davis \& Co., United Kingdom) and exsanguinated by cardiac puncture. Blood samples were collected for biochemical analyses. The liver and epididymal fat were harvested and weighted. All experimental procedures performed in the study were authorized by the Institutional Animal Care and Use Committee. 


\section{Biochemical measures}

Blood glucose concentration was determined by the enzymatic glucose analyzer, Glucometer Elite (Bayer, Elkhart, IN) on blood samples taken from the tail vein. Plasma samples that were obtained from EDTA-treated blood samples by separation at $12,000 \times \mathrm{g}$ for $15 \mathrm{~min}$, were stored until lipid analysis, at $-80^{\circ} \mathrm{C}$. Then, an aliquot was analyzed for total cholesterol, TG and HDL-cholesterol concentrations by colorimetric methods (Boehringer Mannheim, Mannheim, Germany). Insulin levels in plasma were assessed by radioimmunoassay using a human primary antibody (Phadesph; Kabi Pharmacia Diagnostics, Uppsala, Sweden) according to the manufacturer's instructions.

\section{Lipid extraction from liver samples}

The liver samples were weighed and homogenized with saline at a ratio of 1:5 (w:v) in plastic tubes on ice. Lipids were extracted from an aliquot of the liver homogenate according to the procedure of Folch et al. [24]. The total amount of fat was calculated according to Leikin-Frenkel et al. [25].

\section{Data Analysis}

Data was expressed as means \pm SD and statistical significance was taken as $P<0.05$. Data was analyzed by oneway analysis of variance (ANOVA) model for continuous variables to assess the differences among the experimental groups. Fisher exact test was used for comparison of nonparametric variables, namely, gerbil survival, and the number of gerbils in phase $\mathrm{C}, \mathrm{D}$, or presenting normoglycemia. The assumption of normal distribution and homogeneity of variance was tested for all outcome measures. Accordingly, the differences between groups were evaluated by two-tailed Student's $t$-test or Wilcoxon's signedrank test. Spearman's rank-order correlation coefficient was used to evaluate the associations between changes in insulin and in blood glucose levels at the intervention endpoint. The statistical analyses were carried out by using SPSS statistical software (SSPS Inc, Chicago, IL) version 13.0 .

\section{Results}

Animals

By the end of the 4.5 weeks intervention, 3 gerbils from the control group had normal blood glucose levels (below $140 \mathrm{mg} / \mathrm{dl}$ ), 22 presented typical phase C profile, one gerbil presented typical phase D symptoms (triglyceride levels above $500 \mathrm{mg} / \mathrm{dl}$ ) and 4 gerbils had died from unrelated causes. Similarly, within the PS-HOSO diet group, 6 animals had normal blood glucose levels, 19 demonstrated phase $\mathrm{C}$ characteristics, 4 gerbils presented typical phase $\mathrm{D}$ symptoms, and one gerbil died. There were no statistically significant differences between the two groups in the numbers of animal in phase C, phase $\mathrm{D}$, animal with normal glucose levels, or dead animals. The baseline body weights and blood glucose levels of the gerbils are shown in Table 1. No significant differences among the various groups were evident.

Table I: Baseline characteristics of tested gerbils'.

\begin{tabular}{|c|c|c|c|c|c|c|c|c|c|c|c|c|}
\hline & \multicolumn{6}{|c|}{ All tested gerbils } & \multicolumn{6}{|c|}{ Gerbils in phase $C$} \\
\hline & \multicolumn{3}{|c|}{ Control } & \multicolumn{3}{|c|}{ PS-HOSO } & \multicolumn{3}{|c|}{ Control } & \multicolumn{3}{|c|}{ PS-HOSO } \\
\hline & Total & $\begin{array}{c}\text { Non- } \\
\text { fasting }\end{array}$ & Fasting & Total & $\begin{array}{c}\text { Non- } \\
\text { fasting }\end{array}$ & Fasting & Total & $\begin{array}{c}\text { Non- } \\
\text { fasting }\end{array}$ & Fasting & Total & $\begin{array}{c}\text { Non- } \\
\text { fasting }\end{array}$ & Fasting \\
\hline $\mathbf{n}$ & 30 & 16 & 14 & 30 & 14 & 16 & 22 & 10 & 12 & 19 & 8 & II \\
\hline $\begin{array}{l}\text { Body } \\
\text { weight } \\
\text { (gr) }\end{array}$ & $\begin{array}{c}162.40 \pm \\
22.7\end{array}$ & $\begin{array}{c}156.94 \pm \\
24.5\end{array}$ & $\begin{array}{c}168.64 \pm \\
19.5\end{array}$ & $\begin{array}{c}163.93 \pm \\
26.2\end{array}$ & $\begin{array}{c}169.43 \pm \\
32.4\end{array}$ & $\begin{array}{c}159.13 \pm \\
19.2\end{array}$ & $\begin{array}{c}167.14 \pm \\
20.2\end{array}$ & $\begin{array}{c}163.6 \pm \\
25.7\end{array}$ & $\begin{array}{c}170.08 \pm \\
14.6\end{array}$ & $\begin{array}{c}|59.2| \pm \\
27.5\end{array}$ & $\begin{array}{c}160.50 \pm \\
35.9\end{array}$ & $\begin{array}{c}158.27 \pm \\
21.3\end{array}$ \\
\hline $\begin{array}{l}\text { Glucose } \\
\text { (mg/dL) }\end{array}$ & $\begin{array}{c}73.97 \pm \\
8.0\end{array}$ & $\begin{array}{c}72.63 \pm \\
6.9\end{array}$ & $\begin{array}{c}75.50 \pm \\
9.2\end{array}$ & $\begin{array}{c}72.40 \pm \\
10.1\end{array}$ & $\begin{array}{c}76.93 \pm \\
11.0\end{array}$ & $\begin{array}{c}* 68.44 \pm \\
7.5\end{array}$ & $\begin{array}{c}73.77 \pm \\
7.2\end{array}$ & $\begin{array}{c}72.30 \pm \\
7.6\end{array}$ & $\begin{array}{c}75.00 \pm \\
7.0\end{array}$ & $\begin{array}{c}72.05 \pm \\
9.6\end{array}$ & $\begin{array}{c}75.75 \pm \\
11.5\end{array}$ & $\begin{array}{c}69.36 \pm \\
7.3\end{array}$ \\
\hline
\end{tabular}

Psammomys obesus were weighted and tested for blood glucose levels at the beginning of the experiment. Following 4.5 weeks of experimental diet feeding, half of each animal group were deprived of food for $16 \mathrm{~h}$. Statistical significance between baseline values of control and PS-HOSO treatments was calculated for the gerbils that started the feeding period (all gerbils, total), for the subgroup that was later assigned to fast (all gerbils, fasting) and the subgroup that was not assigned to fast (all gerbils, non-fasting). Statistical significance was also calculated for gerbils that were in phase $C$ at endpoint (phase $C$, total), for phase $C$ gerbils that were not assigned to fast (phase $C$, non-fasting) and for phase $C$ gerbils that were assigned to fast (phase $C$, fasting).

IValues are means \pm S.D

$* P<0.05$

PS-HOSO: plant sterol esterified with high oleic sunflower oil. 


\section{Body weight, liver weight and fat accumulation of phase $C$ gerbils}

PS-HOSO effect on body weight, liver weight and fat accumulation is shown in Table 2. Animals fed PS-HOSO and assigned to the fasting mode reduced $(P=0.045) 6.7 \%$ in their body weight as compared to the control diet fed animals. The relative amount of white adipose tissue, as determined by the ratio $(\mathrm{w} / \mathrm{w})$ of epididymal fat to liver decreased $(P=0.044)$ by $16 \%$ compared to the corresponding control group. None of the above mentioned effects were observed in the non-fasting group. Liver weight at the end of the study was $11 \%$ smaller $(P=$ 0.039 ) among non-fasting animals in the control group, as compared to non-fasting animals in the PS-HOSO group. This difference was abolished in the fasting groups. Analysis of liver fat weight to liver weight ratio didn't reveal any significant difference between treatment groups among non-fasting animals, indicating that the liver weight difference didn't result from liver fat accumulation. Interestingly, among fasting animals, this ratio was $27 \%$ lower $(P=0.04)$ in the PS-HOSO group in comparison with that of the control group.

\section{Biochemical measures of Phase $\boldsymbol{C}$ gerbils}

Treatment with PS-HOSO significantly reduced the plasma levels of TC and non-HDL cholesterol by $24 \%(P$ $=0.001)$ and $34 \%(P=0.002)$, respectively, compared to the control diet (Figure 1). When the fasting and non-fasting groups of phase $\mathrm{C}$ gerbils were analyzed separately, total cholesterol was reduced $(P=0.002)$ by $28 \%$ in the PS-HOSO treated non-fasting animals, and tended to decrease $(P=0.16)$ by $20.5 \%$ in the fasting group, as com- pared to the control-fed animals (data not shown). NonHDL cholesterol concentrations tended to decrease $(P=$ 0.064 ) by $37 \%$ in the PS-HOSO treated non-fasting animals, and decreased $(P=0.049)$ by $31 \%$ in the fasting animals, as compared to the control groups (data not shown).

No significant differences in blood glucose levels between the PS-HOSO-fed animals and the control diet-fed animals were detected at the end of the experimental diets intake (Table 3). The glucose levels among all of phase $\mathrm{C}$ gerbils, prior to fasting assignment, were elevated (280$340 \mathrm{mg} / \mathrm{dl}$ ) as indicated by the three last glucose measurements (data not shown). The plasma levels of insulin dropped $(P<0.0001)$ by $39 \%$ at the endpoint of the experiment in the phase C PS-HOSO group, compared to the control (Table 3). Comparable findings were shown when the fasting and non-fasting groups were analyzed separately in the fasting $(44 \% ; P<0.0001)$ and non-fasting $(33 \% ; P=0.014)$ groups.

In order to test the possibility that the insulin level reduction observed in the PS-HOSO gerbils was caused by $\beta$-cell degranulation and deterioration toward phase $\mathrm{D}$, we plotted plasma insulin vs. blood glucose for each separate animal (Figure 2). There was no correlation between the insulin levels and the glucose levels in PS-HOSO animals, regardless of the feeding regime, indicating that the insulin reduction is probably not caused by $\beta$-cell degranulation. Another indication for the animals not being in phase $\mathrm{D}$ is the fact that they were screened for blood TG levels of below $500 \mathrm{mg} / \mathrm{dl}$.

Table 2: PS-HOSO effect on body weight, liver weight and fat accumulation of phase $\mathrm{C}$ gerbils'.

\begin{tabular}{ccccccc}
\hline & \multicolumn{3}{c}{ Control } & & PS-HOSO \\
\hline & Total & Non-fasting & Fasting & Total & Non-fasting & Fasting \\
\hline Bodyweight at endpoint $(\mathrm{gr})$ & $219.05 \pm 16.2$ & $214.60 \pm 15.8$ & $222.75 \pm 16.2$ & $211.58 \pm 19.8$ & $216.63 \pm 23.0$ & $* 207.91 \pm 17.3$ \\
\hline Liver weight (gr) & $8.23 \pm 0.77$ & $8.36 \pm 0.80$ & $8.12 \pm 0.77$ & $8.68 \pm 1.19$ & $* 9.40 \pm 1.17$ & $8.15 \pm 0.93$ \\
\hline Liver fat weight to liver weight ratio & $0.11 \pm 0.03$ & $0.10 \pm 0.02$ & $0.11 \pm 0.04$ & $* 0.08 \pm 0.01$ & $0.08 \pm 0.08$ & $* 0.08 \pm 0.01$ \\
\hline Epididymal fat weight (gr) & $6.35 \pm 0.94$ & $6.25 \pm 0.96$ & $6.43 \pm 0.95$ & $5.88 \pm 1.73$ & $6.54 \pm 2.30$ & $* 5.41 \pm 1.06$ \\
\hline Epididymal fat to liver weight ratio & $0.78 \pm 0.14$ & $0.75 \pm 0.12$ & $0.80 \pm 0.15$ & $0.68 \pm 0.18$ & $0.69 \pm 0.25$ & $* 0.67 \pm 0.14$ \\
\hline
\end{tabular}

Psammomys obesus were fed with Control or PS-HOSO as described in the method section and were monitored for body weight. Following 4.5 weeks of experimental diet feeding, half of each animal group was deprived of food for $16 \mathrm{~h}$ and then all animals were weighted and exsanguinated. The liver and epididymal fat were harvested and weighted. Liver fat of 15 PS-HOSO treated animals ( 9 and 6 from the fasting and non-fasting groups, respectively) and 16 control treated animals ( 7 and 9 from the fasting and non-fasting groups, respectively) was extracted and weighted. Statistical significance between endpoint values of control and PS-HOSO treatments were calculated for all of phase $\mathrm{C}$ gerbils (total), and for fasting and non-fasting phase $C$ gerbils.

IValues are means \pm S.D

$* P<0.05$.

PS-HOSO: plant sterol esterified with high oleic sunflower oil. 

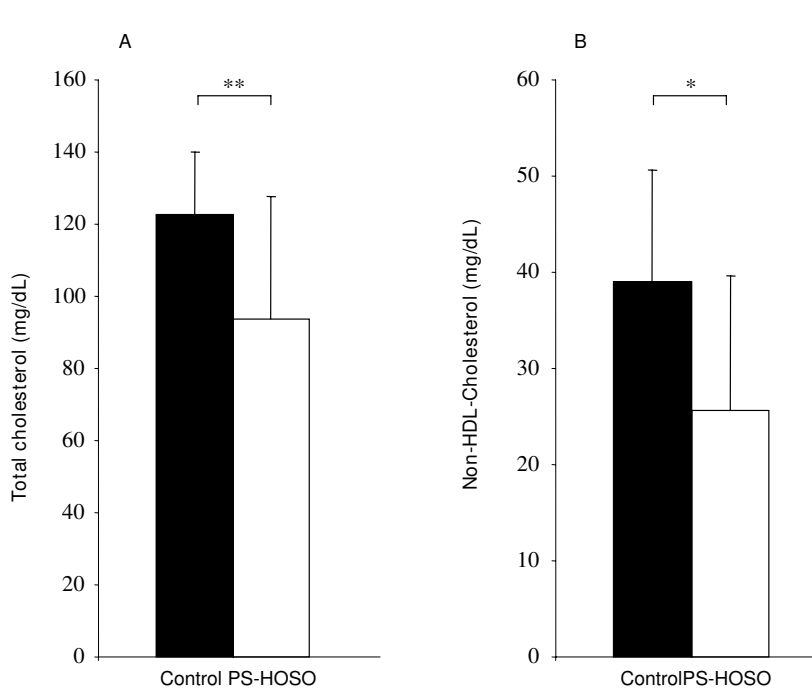

Figure I

Effect of PS-HOSO on plasma lipid levels of phase C gerbils. Psammomys obesus were fed with control (closed bars) or PS-HOSO (open bars) as described in the method section. Following 4.5 weeks of experimental diet feeding, total cholestrol (A) and non-HDL cholesterol (B) were measured. Results are means \pm SD. Statistical significance between endpoint values of control and PS-HOSO treatments are * P-Value < 0.0I, ** P-Value < 0.00I. PS-HOSO: plant sterol esterified with high oleic sunflower oil.

The effect of PS-HOSO feeding on the insulin levels is strikingly evident from Figure 2 as the insulin measurement values of the PS-HOSO-fed animals cluster in the bottom end of the scale, compared to those of the control diet-fed animals.

\section{Discussion}

The aim of this study was to test the effect of PS-HOSO, a novel preparation of plant sterols esterified to high oleic sunflower oil fatty acids mixed with 1,3-DAG, in a matrix of high oleic sunflower oil, on the development of metabolic syndrome and diabetic symptoms in Psammomys obesus. PS have been intensely studied in recent years and have shown to lower TC and LDL-C. These effects are obtained mainly by reducing the intestinal absorption of dietary and biliary cholesterol [26,9]. Current hypotheses ascribe a vital role to the dysfunction of lipid metabolism in the development of metabolic syndrome and type 2 diabetes $[27,28]$. Thus, we chose to test the effect of PSHOSO preparation in the gerbil Psammomys obesus which serves as a model of nutritionally induced type 2 diabetes. The progression of metabolic syndrome, and the subsequent diabetes mellitus, in these animals, resembles in many aspects the development of metabolic syndrome and diabetes in susceptible humans $[19,20]$.

In this study, PS-HOSO treatment significantly reduced the TC and non-HDL cholesterol among phase $\mathrm{C}$ gerbils, compared to control diet treatment. These results are in agreement with an animal study performed on Apolipoprotein E-deficient mice [22] which demonstrated that administration of PS esters of canola oil fatty acids in a canola oil matrix strongly tended to lower TC levels. Similarly, a human study performed on hypercholesterolemic, mildly overweight individuals [23] showed that administration of PS esterified to olive oil in an olive oil based matrix, significantly reduced LDL levels. These results indicate that PS maintains their cholesterol lowering properties when esterified to high oleic sunflower oil fatty acids.

Interestingly, treatment with PS-HOSO significantly reduced body weight and the amount of epididymal fat among fasting phase $\mathrm{C}$ gerbils in comparison with the control group. The reason for this reduction is not clear, however, 1,3-DAG, a component of PS-HOSO, has been previously reported to reduce the extent of postprandial TG increase [29] and to reduce body fat in obese individuals [30]. It is assumed that 1,3-DAG-rich diet is less readily reesterified into chylomicron-TG moiety, thereby

Table 3: PS-HOSO effect on glucose and insulin levels of phase $C$ gerbils'.

\begin{tabular}{cccccccc}
\hline & \multicolumn{3}{c}{ Control } & & PS-HOSO \\
\hline & Total & Non-fasting & Fasting & Total & Non-fasting & Fasting \\
\hline Glucose at endpoint $(\mathrm{mg} / \mathrm{dL})$ & $169.41 \pm 106.7$ & $271.70 \pm 62.2$ & $84.17 \pm 33.4$ & $180.16 \pm 136.6$ & $296.38 \pm 143.0$ & $95.64 \pm 24.6$ \\
\hline Insulin at endpoint $(\mu \mathrm{lu} / \mathrm{L})$ & $211.36 \pm 61.0$ & $228.60 \pm 67.1$ & $197.00 \pm 54.0$ & $* * * 128.37 \pm 45.7$ & $* 153.63 \pm 40.3$ & $* * * 110.00 \pm 41.6$ \\
\hline
\end{tabular}

Psammomys obesus were fed with control or PS-HOSO as described in the method section and were monitored for blood glucose levels. Following 4.5 weeks of experimental diet feeding, half of each animal group was deprived of food for $16 \mathrm{~h}$ and then all animals were tested for blood glucose and insulin levels. Statistical significance between endpoint values of control and PS-HOSO treatments were calculated for all of phase $\mathrm{C}$ gerbils (total), and for fasting and non-fasting phase $C$ gerbils.

IValues are means \pm S.D

$* P<0.05 ., * * P<0.0001$.

PS-HOSO: plant sterol esterified with high oleic sunflower oil. 


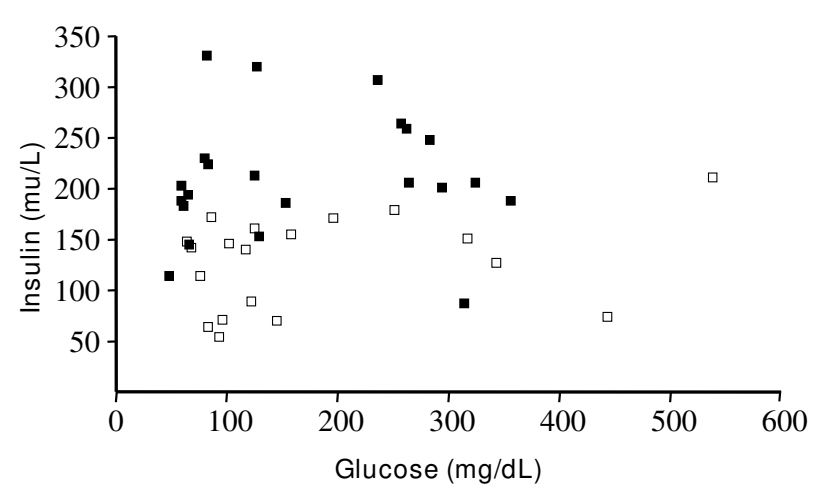

Figure 2

Effect of PS-HOSO on plasma insulin levels versus blood glucose levels of phase $\mathbf{C}$ gerbils. Psammomys obesus were fed with control (closed squares) or PS-HOSO (open squares) as described in the method section. Following 4.5 weeks of experimental diet feeding, the correlation between plasma insulin and blood glucose levels was tested. There was no correlation between plasma insulin and blood glucose levels among PS-HOSO fed animals $(r=0.318 ; n=$ 19; $P=0.185)$, nor among control fed animals $(r=0.17 ; n=$ $22 ; P=0.448)$. PS-HOSO: plant sterol esterified with high oleic sunflower oil.

reducing the transport of dietary neutral lipids to the blood circulation and their deposit in adipose tissue [31]. Instead, 1,3-DAG may be devoted to substantially enhance $\beta$-oxidation, resulting in a decrease in abdominal body fat and weight [32-34]. However, these results were obtained following administration of higher doses of 1,3DAG than the present study dosage and thus, the mechanism of by which PS-HOSO reduce fat accumulation remains to be elucidated. It should be noted that liver weight among phase $\mathrm{C}$, non-fasting gerbils in the PSHOSO group was greater than that of the non-fasting gerbils in the control group. However, the possibility that PSHOSO treated animals developed a fatty liver was excluded by measuring the amount of liver total fat. There was no significant difference between the non-fasting groups in the ratio of liver fat weight to liver weight. The difference in liver weight at non-fasting state may be explained by modifications in postprandial hepatic glycogen metabolism. Human studies have shown that after meal, glycogen accumulation in type 2 diabetic patients rise to a lesser extent in comparison with non-diabetic subjects $[35,36]$. Thus, greater liver weight may even indicate an ameliorating effect of PS-HOSO on the type 2 diabetic metabolic defects, influencing hepatic glycogen storage. In addition, glycogen metabolic differences, as the cause for liver weight difference between the groups, may be further supported by the fact that, among fasting groups, the described difference in liver weight between PS-HOSO and control groups was abolished. In fact, in this group, the ratio of liver fat weight to liver weight was smaller among PS-HOSO treated animals in comparison with control treated animals, indicating the possible role of PS-HOSO in reducing liver fat accumulation.

It is well established today that adipose tissue does not function solely as an energy storage compartment, but it is also endowed with diverse regulatory roles thanks to a complex system of endocrine regulation that affects energy intake and distribution [37]. Increases in body fat mass are accompanied by elevation of free fatty acids, leptin and insulin $[38,39,33]$. In the present study, PS-HOSO did not only affect fat accumulation and storage, but it also caused a dramatic reduction in circulating insulin levels. Several studies that analyzed the effects of plant sterols in type 2 diabetic subjects did not report insulin levels [40-42], and, to the best of our knowledge, this is the first investigation that deals with the impact of phytosterol on insulin concentrations. It is possible that the insulin reduction can be attributed to the presence of 1,3-DAG since previous studies emphasized its relationship with serum insulin reduction both in animal models [33] and subjects with type 2 diabetes mellitus [43]. Although the amount of DAG in PS-HOSO is relatively low, compared to the amount used in the above-mentioned studies, it is still possible that some synergistic effect between DAG and the plant sterols takes place.

In addition, it was recently shown that oleate might have a role in protecting against palmitate-induced inflammation and insulin resistance in skeletal muscle cells [44]. It is thus possible that the oleic acid in the PS-HOSO preparation contributes as well to the significant insulin reduction recorded with PS-HOSO.

In contrast to the reduction in insulin levels, fasting blood glucose levels (glucose at endpoint) remained unchanged in the PS-HOSO treated gerbils compared to the control diet fed gerbils. This confirms the results from a published phytosterol study in subjects with type 2 diabetes in which no change was detected in blood glucose levels, despite lipid profile improvement [41]. Hypoinsulinemia in combination with hyperglycemia are characteristics of phase D gerbils, however, as shown in Figure 2 there was no correlation between blood glucose levels and plasma insulin levels among PS-HOSO fed gerbils. In addition, the animals were clearly not in phase $\mathrm{D}$, since their triglyceride levels were not elevated.

\section{Conclusion}

Hyperinsulinemia is a hallmark of metabolic syndrome and type 2 diabetes and it is necessary to keep it under control. We show here that PS-HOSO, as a dietary supplement, can help achieve this aim together with other desirable therapeutic goals such as weight loss, fat reduction 
and the lowering of blood cholesterol levels. These data warrant further evaluation of PS-HOSO as a functional ingredient for pre-diabetic populations.

\section{Competing interests}

DP, TC are Directors of Clinical Studies and YH, TD are Project Managers at Enzymotec LTD. EZ, NP and RK have no competing interests. This study was funded by Enzymotec LTD, Israel.

\section{Authors' contributions}

EZ designed the study. NP and RK carried out all aspects of the animal studies. DP participated in the design of the study, animal studies and performed statistical analysis. YH was responsible for drafting the manuscript and participated in data analyses. TD participated in drafting the manuscript, and data analyses. TC participated in the design of the study, participated in animal studies and data analyses. All authors participated in data interpretation. All authors have read and approved this manuscript.

\section{Acknowledgements}

We thank Dr. Alicia Leikin-Frenkel (Minerva Center for Cholesterol Gallstones and Lipid Metabolism in the Liver, Tel Aviv University, Tel-Aviv, Israel) for analysing liver extractions.

\section{References}

I. Groop L, Orho-Melander M: The dysmetabolic syndrome. J Intern Med 200I, 250(2): I05-I 20.

2. Kereiakes DJ, Willerson JT: Metabolic syndrome epidemic. Circulation 2003, 108(13): I552-I553.

3. Kahn SE, Hull RL, Utzschneider KM: Mechanisms linking obesity to insulin resistance and type 2 diabetes. Nature 2006, 444(7 I 2 I):840-846.

4. Miyazaki Y, Glass L, Triplitt C, Wajcberg E, Mandarino LJ, DeFronzo RA: Abdominal fat distribution and peripheral and hepatic insulin resistance in type 2 diabetes mellitus. Am J Physiol Endocrinol Metab 2002, 283(6): EI I 35-I I 43.

5. Ruotolo G, Howard BV: Dyslipidemia of the metabolic syndrome. Curr Cardiol Rep 2002, 4(6):494-500.

6. Costa J, Borges M, David C, Vaz Carneiro A: Efficacy of lipid lowering drug treatment for diabetic and non-diabetic patients: meta-analysis of randomised controlled trials. Bmj 2006, 332(7550): III - II 24.

7. Fox CS, Coady S, Sorlie PD, Levy D, Meigs JB, D'Agostino RB Sr, Wilson PW, Savage PJ: Trends in cardiovascular complications of diabetes. Jama 2004, 292(20):2495-2499.

8. Jenkins DJ, Kendall CW, Marchie A, Faulkner DA, Wong JM, de Souza R, Emam A, Parker TL, Vidgen E, Trautwein EA, et al.: Direct comparison of a dietary portfolio of cholesterol-lowering foods with a statin in hypercholesterolemic participants. Am J Clin Nutr 2005, 81 (2):380-387.

9. Jones PJ, MacDougall DE, Ntanios F, Vanstone CA: Dietary phytosterols as cholesterol-lowering agents in humans. Can J Physiol Pharmacol 1997, 75(3):217-227.

10. Mattson FH, Grundy SM: Comparison of effects of dietary saturated, monounsaturated, and polyunsaturated fatty acids on plasma lipids and lipoproteins in man. J Lipid Res 1985, 26(2): 194-202.

11. Kratz M, Cullen P, Kannenberg F, Kassner A, Fobker M, Abuja PM, Assmann G, Wahrburg U: Effects of dietary fatty acids on the composition and oxidizability of low-density lipoprotein. Eur J Clin Nutr 2002, 56(I):72-8I.

12. Kris-Etherton PM, Pearson TA, Wan Y, Hargrove RL, Moriarty K, Fishell V, Etherton TD: High-monounsaturated fatty acid diets lower both plasma cholesterol and triacylglycerol concentrations. Am J Clin Nutr 1999, 70(6): 1009-1015.
13. Puiggros C, Chacon P, Armadans LI, Clapes J, Planas M: Effects of oleic-rich and omega-3-rich diets on serum lipid pattern and lipid oxidation in mildly hypercholesterolemic patients. Clin Nutr 2002, 2 I ( I):79-87.

14. Katan MB, Grundy SM, Jones P, Law M, Miettinen T, Paoletti R: Efficacy and safety of plant stanols and sterols in the management of blood cholesterol levels. Mayo Clin Proc 2003, 78(8):965-978.

15. Ikeda I, Sugano M: Some aspects of mechanism of inhibition of cholesterol absorption by beta-sitosterol. Biochim Biophys Acta 1983, 732(3):65I-658.

16. Heinemann T, Kullak-Ublick GA, Pietruck B, von Bergmann K: Mechanisms of action of plant sterols on inhibition of cholesterol absorption. Comparison of sitosterol and sitostanol. Eur J Clin Pharmacol I99I, 40(Suppl I):S59-63.

17. Ostlund RE Jr: Phytosterols, cholesterol absorption and healthy diets. Lipids 2007, 42(I):4I-45.

18. Weststrate JA, Meijer GW: Plant sterol-enriched margarines and reduction of plasma total- and LDL-cholesterol concentrations in normocholesterolaemic and mildly hypercholesterolaemic subjects. Eur J Clin Nutr 1998, 52(5):334-343.

19. Shafrir E, Gutman A: Psammomys obesus of the Jerusalem colony: a model for nutritionally induced, non-insulin-dependent diabetes. J Basic Clin Physiol Pharmacol 1993, 4(I-2):83-99.

20. Kalman R, Ziv E, Shafrir E, Bar-On H, Perez R: Psammomys obesus and the albino rat--two different models of nutritional insulin resistance, representing two different types of human populations. Lab Anim 200I, 35(4):346-352.

21. Kalderon B, Gutman A, Levy E, Shafrir E, Adler JH: Characterization of stages in development of obesity-diabetes syndrome in sand rat (Psammomys obesus). Diabetes 1986, 35(6):717-724.

22. Fuhrman B, Plat D, Herzog Y, Aviram M: Consumption of a novel dietary formula of plant sterol esters of canola oil fatty acids, in a canola oil matrix containing I,3-diacylglycerol, reduces oxidative stress in atherosclerotic apolipoprotein E-deficient mice. J Agric Food Chem 2007, 55(5):2028-2033.

23. Chan YM, Demonty I, Pelled D, Jones PJ: Olive oil containing olive oil fatty acid esters of plant sterols and dietary diacylglycerol reduces low-density lipoprotein cholesterol and decreases the tendency for peroxidation in hypercholesterolaemic subjects. BrJ Nutr 2007, 98(3):563-570.

24. Folch J, Lees M, Sloane Stanley GH: A simple method for the isolation and purification of total lipides from animal tissues. J Biol Chem 1957, 226(I):497-509.

25. Leikin-Frenkel A, Goldiner I, Leikin-Gobbi D, Rosenberg R, Bonen H, Litvak A, Bernheim J, Konikoff FM, Gilat T: Treatment of preestablished diet-induced fatty liver by oral fatty acid-bile acid conjugates in rodents. Eur J Gastroenterol Hepatol 2008, 20(12): $1205-1213$.

26. Brufau G, Canela MA, Rafecas M: Phytosterols: physiologic and metabolic aspects related to cholesterol-lowering properties. Nutr Res 2008, 28(4):217-225.

27. Krauss RM: Lipids and lipoproteins in patients with type $\mathbf{2}$ diabetes. Diabetes Care 2004, 27(6): I496- I504.

28. Shafrir E, Raz I: Diabetes: mellitus or lipidus? Diabetologia 2003, 46(3):433-440.

29. Taguchi H, Watanabe H, Onizawa K, Nagao T, Gotoh N, Yasukawa T, Tsushima R, Shimasaki H, Itakura H: Double-blind controlled study on the effects of dietary diacylglycerol on postprandial serum and chylomicron triacylglycerol responses in healthy humans. J Am Coll Nutr 2000, 19(6):789-796.

30. Maki KC, Davidson MH, Tsushima R, Matsuo N, Tokimitsu I, Umporowicz DM, Dicklin MR, Foster GS, Ingram KA, Anderson BD, et al.: Consumption of diacylglycerol oil as part of a reducedenergy diet enhances loss of body weight and fat in comparison with consumption of a triacylglycerol control oil. Am J Clin Nutr 2002, 76(6): 1230-1236.

31. Yasunaga K, Glinsmann WH, Seo Y, Katsuragi Y, Kobayashi S, Flickinger B, Kennepohl E, Yasukawa T, Borzelleca JF: Safety aspects regarding the consumption of high-dose dietary diacylglycerol oil in men and women in a double-blind controlled trial in comparison with consumption of a triacylglycerol control oil. Food Chem Toxicol 2004, 42(9): I4| 9-1429. 
32. Murata M, Ide T, Hara K: Reciprocal responses to dietary diacylglycerol of hepatic enzymes of fatty acid synthesis and oxidation in the rat. 1997, 77:107-121.

33. Murase T, Mizuno T, Omachi T, Onizawa K, Komine $\mathrm{Y}$, Kondo H, Hase T, Tokimitsu I: Dietary diacylglycerol suppresses high fat and high sucrose diet-induced body fat accumulation in C57BL/6J mice. J Lipid Res 200I, 42(3):372-378.

34. Murase T, Aoki M, Wakisaka T, Hase T, Tokimitsu I: Anti-obesity effect of dietary diacylglycerol in C57BL/6J mice: dietary diacylglycerol stimulates intestinal lipid metabolism. J Lipid Res 2002, 43(8): $1312-1319$.

35. Roden $M$, Bernroider $E$ : Hepatic glucose metabolism in humans--its role in health and disease. Best Pract Res Clin Endocrinol Metab 2003, I7(3):365-383.

36. Krssak M, Brehm A, Bernroider E, Anderwald C, Nowotny P, Dalla Man C, Cobelli C, Cline GW, Shulman GI, WaldhausI W, et al:: Alterations in postprandial hepatic glycogen metabolism in type 2 diabetes. Diabetes 2004, 53( I 2):3048-3056.

37. Mohamed-Ali V, Pinkney JH, Coppack SW: Adipose tissue as an endocrine and paracrine organ. Int J Obes Relat Metab Disord 1998, 22(I 2): I I45-II58.

38. Muller G, Ertl J, Gerl M, Preibisch G: Leptin impairs metabolic actions of insulin in isolated rat adipocytes. J Biol Chem 1997 272(16): 10585-10593.

39. Boden G: Role of fatty acids in the pathogenesis of insulin resistance and NIDDM. Diabetes 1997, 46(I):3-10.

40. Hayes KC, Pronczuk A, Perlman D: Nonesterified phytosterols dissolved and recrystallized in oil reduce plasma cholesterol in gerbils and humans. J Nutr 2004, I 34(6): 1395-1399.

4I. Lee YM, Haastert B, Scherbaum W, Hauner H: A phytosterolenriched spread improves the lipid profile of subjects with type 2 diabetes mellitus--a randomized controlled trial under free-living conditions. Eur J Nutr 2003, 42(2): I I I- I I 7.

42. Lau VW, Journoud M, Jones PJ: Plant sterols are efficacious in lowering plasma LDL and non-HDL cholesterol in hypercholesterolemic type 2 diabetic and nondiabetic persons. Am J Clin Nutr 2005, 8I(6): | 35 I- I 358.

43. Li D, Xu T, Takase H, Tokimitsu I, Zhang P, Wang Q, Yu X, Zhang A: Diacylglycerol-induced improvement of whole-body insulin sensitivity in type 2 diabetes mellitus: a long-term randomized, double-blind controlled study. Clin Nutr 2008, 27(2):203-2II.

44. Coll T, Eyre E, Rodriguez-Calvo R, Palomer X, Sanchez RM, Merlos M, Laguna JC, Vazquez-Carrera M: Oleate Reverses Palmitateinduced Insulin Resistance and Inflammation in Skeleta Muscle Cells. J Biol Chem 2008, 283(I7): I I 107-II II6.
htp.//Www.lipidworld.com/content/8/1/42

\section{Publish with Bio Med Central and every scientist can read your work free of charge}

"BioMed Central will be the most significant development for disseminating the results of biomedical research in our lifetime. "

Sir Paul Nurse, Cancer Research UK

Your research papers will be:

- available free of charge to the entire biomedical community

- peer reviewed and published immediately upon acceptance

- cited in PubMed and archived on PubMed Central

- yours - you keep the copyright

Submit your manuscript here:

http://www.biomedcentral.com/info/publishing_adv.asp
BiolMedcentral 